Fecha de recepción: mayo 2021 Fecha de aceptación: junio 2021 Versión final: julio 2021

\section{De pícaros y chantas: la configuración del estereotipo entre la literatura y el cine}

Lucía Rodríguez Riva ${ }^{(1)}$

Resumen: Entre las figuras típicas para representar a los sectores populares en el cine argentino se encuentra el chanta. Este personaje sintetiza características de los pícaros españoles, así como también incorpora la herencia de los actores populares italianos. Desde Arlequino hasta el Lazarillo, ambas tradiciones de representación se entrecruzan para dar como resultado un tipo con particularidades locales. En este artículo, me propongo reconstruir la aparición del "pícaro" en la literatura argentina y establecer nexos con la cinematografía nacional. Así, este trabajo puede comprenderse dentro de la imagología, área de estudios dedicada a la revisión crítica de las caracterizaciones nacionales, cuyo objetivo es comprender los discursos generados sobre una sociedad entendiendo que las "imágenes no reflejan identidades, sino que constituyen posibles identificaciones" (Leerssen, 2007). Parto de la noción de estereotipo como una figura que sintetiza a la vez que ayuda a consolidar ciertos imaginarios sociales (Amossy y Herschberg Pierrot, 2010). La perspectiva metodológica para indagar en esta construcción identitaria de lo plebeyo es la historia cultural.

Palabras clave: personaje popular - pícaro - chanta - estereotipo - imagología - literatura comparada - historia cultural.

[Resúmenes en inglés y portugués en la página 91]

${ }^{(1)}$ Es licenciada en Artes (Universidad de Buenos Aires) y productora audiovisual (TEA Imagen). Se encuentra finalizando el doctorado en Historia y Teoría de las Artes (Facultad de Filosofía y Letras, UBA) con una beca interna de Conicet. Es docente de Historia del Cine Latinoamericano y Argentino en la UBA y de Historia del Cine Argentino en la Universidad Nacional de las Artes. 


\section{Introducción}

Hay personajes que atraviesan dispositivos y géneros. Muchas veces, constituyen figuras que condensan formas e idiosincrasias de un determinado pueblo. En el caso argentino, una de ellas es el "chanta". Me refiero a un sujeto urbano masculino cuyo objetivo principal es evitar el trabajo formal. Para lograrlo, lleva a cabo estafas de baja escala que habitualmente implican el montaje de una puesta en escena o de algún tipo de representación. Además, utiliza sus habilidades seductoras y su labia para convencer tanto a sus víctimas como a sus cómplices. Se trata de un personaje atractivo para analizar en la medida en que sus tácticas exhiben posibilidades autorreflexivas sobre él mismo, así como también permiten ofrecer una mirada crítica sobre el mundo en el que se inscribe.

Con un extenso despliegue en la cinematografía argentina, que permite encontrarlo tanto en obras del período industrial como en otras del cine posclásico ${ }^{1}$, el cine ha resultado un espacio privilegiado para su desarrollo. Chingolo (Lucas Demare, 1940), Avivato (Enrique Cahen Salaberry, 1949), El negoción (Simón Feldman, 1959), El gordo Villanueva (Julio Saraceni, 1964), Flor de piolas...! (Rubén Cavallotti, 1967), Los chantas (José Martínez Suárez, 1975), Plata dulce (Fernando Ayala, 1982) y Nueve reinas (Fabián Bielinsky, 1999), por mencionar solo unos pocos títulos, constituyen ejemplos significativos. Demuestran la persistencia del tipo en el tiempo y, por lo tanto, su productividad semántica. Uno de los motivos centrales de la alianza entre cine y chanta tuvo que ver con la incorporación del "actor nacional" (Pellettieri, 2001) desde el inicio del desarrollo industrial. Allí, la relación con los cómicos italianos es medular. Sin embargo, en este artículo me interesa indagar en otra arista que considero fundamental para la constitución del estereotipo: el vínculo con la picaresca española. Entonces, propongo que el chanta -en tanto representación privilegiada de ciertos sectores urbanos de la Argentina- halla parte importante de su configuración en la literatura picaresca vernácula y que el aporte más relevante de la literatura a la formación del estereotipo se basa en ser un "cuentero"; esto es, en poseer la capacidad de relatar y convencer, y de ejercitar la palabra como defensa, en tanto expresión de cierta astucia. En este sentido, el accionar propio del chanta se emparenta con el acto creativo literario. Para ello, realizaré un recorrido por las obras que considero fueron capitales para esta relación, analizándolas desde una perspectiva comparada y trazando puentes con adaptaciones cinematográficas.

Indagar en este personaje desde la perspectiva que revisa críticamente las caracterizaciones nacionales sitúa esta investigación dentro del marco de la imagología (Leerssen, 2007, 2012). El objetivo de esta área de estudios es comprender los discursos generados sobre una sociedad, entendiendo que las "imágenes no reflejan identidades, sino que constituyen posibles identificaciones" (Leerssen, 2007: 27). El foco se ubica en las construcciones textuales y de discurso. No pretende construir una teoría sobre la identidad nacional o cultural: "la emergencia actual de la imagología como un estudio crítico de la caracterización nacional solo puede tener lugar después de haberse abandonado la creencia en la 'realidad' de los tipos nacionales como modelos explicatorios" (Leerssen, 2007: 21). Por el contrario, conceptos como cultura, nacionalidad e identidad deben ser utilizados en este campo más como descripciones o como aquello a desentrañar, que como explicaciones. A 
su vez, estos discursos que son "imaginados" tienden a distinguir una nación del resto de la humanidad y al mismo tiempo sugieren una moral o motivación psicológica colectiva. A las asunciones metodológicas de la imagología recién citadas, se suman otras como la necesidad de encontrar la tradición de los tropos que articulan los estereotipos nacionales o culturales.

Se trata, por lo tanto, de examinar de manera crítica los tipos ligados de forma predominante a una cultura. El estereotipo, de acuerdo con Fernández-Montesino (2016) es un fenómeno de reducción y de repetición, que forma parte de las representaciones colectivas, las cuales dependen de los modelos culturales de cada grupo o país y operan de manera cotidiana. Tiene funciones cognitivas (facilita procesos de aprehensión, comprensión y categorización), sociales (favorece la cohesión interna, aunque también puede provocar rechazo hacia lo distinto) y literarias (como un nexo entre autor y lector). El enfoque analítico, por lo tanto, puede encontrarse tanto desde las ciencias sociales como desde los estudios literarios. En este sentido, Ruth Amossy y Anne Herschberg Pierrot consideran el estereotipo "como un objeto transversal" que permite estudiar "la relación de los discursos con los imaginarios sociales" (2010, p. 11). De este modo, el estereotipo es definido como "un esquema colectivo cristalizado que corresponde a un modelo cultural dado", por lo cual se "puede intentar desarmarlo, pero no [se] puede desconocerlo" (ídem, 69). Posee una "bivalencia constitutiva", ya que si por un lado condensa reducciones que derivan en actitudes discriminatorias, por otro lado, son esquemas constructivos y productivos que facilitan la comprensión del mundo (ídem, 56). Es decir, que no se trata de un patrón fijo y estático, sino de una interrelación constante fruto de intercambios culturales y simbolizaciones propias de las artes o los medios de comunicación en contacto con el referente externo.

\section{Tradiciones de consumos: algunas recurrencias}

"La viveza criolla agrega matices a la picardía española, pero, esencialmente, la continúa."

(Pagés Larraya, 1968, p. 674)

La observación precedente indica las relaciones entre el chanta y sus antecedentes literarios. La impronta de la picaresca, corriente iniciada durante el Siglo de Oro Español, se extiende hasta nuestros días. La importancia de la cultura española en el continente americano es irrecusable, por lo cual es preciso considerar la presencia de la literatura española en Argentina no solo entre personas letradas, sino desde la infancia a través del aprendizaje en la escuela. En los colegios secundarios con orientación humanística, un año entero estaba dedicado a la enseñanza de la literatura española. El lazarillo de Tormes (Anónimo, 1554), obra canónica de la picaresca, formaba parte de ese corpus. Actualmente, se ha reorganizado el mapa curricular por cosmovisiones. Aun así, El lazarillo sigue presente como obra recomendada para el último año, destinado a las formas cómicas, paródicas, alegóricas, de ruptura y experimentación (Bracchi y Paulozzo, 2011)². Ahora bien: si estos 
textos son estudiados en el colegio, es porque ocupan un lugar importante dentro de las tradiciones culturales del país. La edición popular de muchos de estos títulos también es prueba de la extensa divulgación que poseían. Libros como El Buscón $n^{3}$ o Rinconete y Cortadillo ${ }^{4}$ formaron parte de la Colección Biblioteca Básica Universal que publicó el Centro Editor de América Latina en 1969, por mencionar una edición popular de las numerosas que se hicieron en el país. Asimismo, resulta un dato sugerente que el investigador español Alonso Zamora Vicente ${ }^{5}$ haya publicado en Buenos Aires Qué es la novela picaresca (1962). Se trata de un estudio breve que propone una síntesis de los rasgos y la evolución del género a través de las obras más sobresalientes, y que se vertebra a través del análisis de El lazarillo. Posiblemente, este intento de sistematización respondiese al interés que el autor hallaba en estos pagos por el género.

Es posible afirmar que a comienzos del siglo XX hubo en Argentina formas vernáculas de la picaresca. Obras como El casamiento de Laucha (1906) y Las divertidas aventuras del nieto de Juan Moreira (1957 [1910]) de Julio Payró presentan una visión de la picaresca adaptada a los usos y costumbres locales. El vínculo con la "novela de iniciación", tal como sostiene José Luis de Diego (1998), permite extender esa tradición hacia otras obras clave de la literatura nacional, como El juguete rabioso (Arlt, 1993 [1926]). En estos casos, el protagonista es el principio estructurante de la obra. Se trata de un varón joven que debe apañárselas para sobrevivir frente a variadas situaciones adversas, las más de las veces también iniciáticas, con las que se enfrenta en su juventud. Con enfoques y estilos muy diversos, lo cierto es que poseen una estructura común (el relato en primera persona en forma de memorias) y a través de este personaje exponen mecanismos injustos de la sociedad a la que pertenecen, así como también los métodos a través de los cuales ellos y otros personajes intentan sobreponerse a esa estructura.

Sin embargo, previo a las novelas de Payró, hubo dos personajes secundarios pero muy importantes en un volumen fundacional para la literatura argentina: el Viejo Vizcacha y Picardía. Hacia el final de La vuelta de Martín Fierro (Hernández, 1950 [1879]), en un momento especialmente reflexivo, el protagonista dedica unos versos a su prole y al hijo del gaucho Cruz, con la intención de transmitir los saberes adquiridos gracias a su experiencia. Fierro recita:

Nace el hombre con la astucia

Que ha de servirle de guía;

Sin ella sucumbiría,

Pero, sigún mi esperencia,

Se vuelve en unos prudencia

Y en los otros, picardía (vv. 4673-4678) (Hernández, 1950, p. 253).

Se trata de una estrofa que condensa una actitud vital hacia la existencia y delimita dos caminos posibles. El de la prudencia estaría encarnado por el propio Fierro y el de la picardía, por Vizcacha. Como ha sido señalado en numerosas ocasiones, esta prédica instructiva es propia de La vuelta del Martín Fierro, que parece ponerse como misión la transmisión de una estructura moral. Así, tras narrar la serie de desgracias que vivió 
desde pequeño y las artimañas que utilizó, Picardía se entera fortuitamente de que es hijo del sargento Cruz y decide honrar su filiación, aunque el peso de su mote se mantiene. A diferencia suyo, Vizcacha no tiene un momento de arrepentimiento y, por lo tanto, tampoco redención. Él es retratado por el hijo segundo de Fierro, quien fuera su ahijado legal:

Viejo lleno de camándulas,

Con un empaque a lo toro;

Andaba siempre en un moro,

Metido en no sé qué enriedos,

Con las patas como loro,

De estribar entre los dedos (vv. 2169-2174)

¡Ah! ¡Viejo más comerciante

en la vida lo he encontrao!

Con ese cuero robao.

Él arreglaba el pastel,

Y allí entre el pulpero y él

Se estendía el certificado (vv. 2187-2193) (Ídem, 1950, pp. 172-173).

Los robos y engaños eran su modo de vida. La voz de Don Vizcacha también quedó registrada en la obra, a través de sus famosos consejos:

El zorro que ya es corrido,

Dende lejos la olfatea;

No se apure quien desea

Hacer lo que le aproveche:

La vaca que más rumea

Es la que da mejor leche. (vv. 2361-2366) (Ídem, 1950, p. 178).

Don Vizcacha expresa una visión escéptica y desconfiada de la vida, que se basa en un estricto apego a su experiencia vital en las circunstancias que lo rodean. Sus consejos apuntan a una pragmática de la individualidad, que desconoce cualquier posibilidad de crear un mundo conjunto. Es una visión absolutamente a la defensiva, que no conoce aliados sino solo potenciales enemigos. Su manera de sobrevivir, por lo tanto, es ajustarse a los objetos del mundo material que le ofrecen algún tipo de bienestar o seguridad, y desconfiar por principio de todo lo demás.

A pesar de las diferencias entre Vizcacha y Picardía, es relevante que sendos personajes encarnan un modo de vida asociado a la trampa, al aprovecharse del otro y a hacer uso de las ocasiones. La moral de Martín Fierro es mudable, pero la de ellos dos es similar6. El hecho de que Picardía busque redimirse incorporándose al ejército responde más bien a necesidades extrínsecas al texto (la denuncia sobre el destino de los gauchos), que al desarrollo propio del personaje. De cualquier manera, ninguno de los dos detenta un final glorioso: Vizcacha muere y Picardía asume los destinos del gaucho incorporándose a un 
ejército que solo lo enviará a la muerte, porque según él "parece que el gaucho tiene / algún pecao que pagar" (vv. 3885-3886, Ídem, p. 226).

Ambos personajes cobraron una enorme popularidad e incluso autonomía de la obra, como estandartes de cierta sabiduría popular. A tal punto es así, que Los consejos del Viejo Vizcacha (Del Campo, 1945) fue el título de una publicación económica que compendiaba versos y rimas de distintas provincias. Allí se encontraba un resumen de todo lo referido a este personaje en el libro de Hernández (la semblanza del hijo segundo, sus consejos, además de versos del Gaucho Cruz y de Picardía), junto a una colección variopinta de poesía popular, con frases, reflexiones y rimas de diversas procedencias. Para Del Campo, Vizcacha operaba como prototipo del gaucho que se encontraba en cualquier rincón del país y representaba al "criollazo de pura cepa", en una visión celebratoria del estereotipo. El repertorio de esta publicación era descripto como una "biblia gaucha." 7 Evidentemente, Don Vizcacha seguía operando como una referencia que aludía a lo cómico y a la astucia plebeya. De una lectura entretenida y amena, que conserva el carácter de la oralidad, su consumo estaba previsto para ser compartido a través de la lectura colectiva. La edición, que poseía una atractiva tapa a colores y un gramaje bajo del papel, era muy económica y estaba destinada a un público popular.

Entonces, si hay que ubicar dónde se encuentra el primer "chanta" en la literatura argentina, es preciso remontarse el Viejo Vizcacha, quien ofrece la "sabiduría de la experiencia". Por el universo rural y el tiempo histórico, alejado aún de las transformaciones que implicarían las migraciones del siglo XX, el Viejo Vizcacha es mucho más afín a la viveza criolla. En Los chantas, el Flaco (Norberto Aroldi) lo utiliza como cita de autoridad en repetidas oportunidades: "Ya lo dijo San Vizcacha (sic), el chanta mayor de la Argentina: el primer deber del hombre es defender el pellejo". En un contexto diferente, cuando Fernando Solanas recupera la historia de José Hernández en Los hijos de Fierro (1972) para ubicarla en sintonía con las luchas revolucionarias de los años sesenta, Vizcacha simboliza la burocracia sindical y se resignifica su alcance, ligándolo a la concepción corrupta y vetusta de la política. Así, el Viejo Vizcacha funciona como un símbolo, una fuente de significados que se reactualiza de maneras diversas en determinados momentos históricos.

\section{Realismo y picaresca}

Otra arista para indagar la influencia de la picaresca se encuentra en el desarrollo de la novela de aprendizaje en la Argentina. Según José Luis de Diego, dentro del marco de la tradición hispana del género se organiza un nuevo realismo que está

basado en la crítica social y política a través de la sátira de las costumbres, en el tono humorístico y en la configuración de un héroe que lejos de resultar un modelo moral, a menudo acumula defectos, picardías nada ejemplares y licencias reñidas con la aceptación social (de Diego, 1998, p. 20). 
Asimismo, el autor selecciona una serie de obras que desplegaron esa tradición en la Argentina, dentro de las cuales ocupan un lugar de importancia las novelas de pícaros de Roberto Payró El casamiento de Laucha (1906) y Divertidas aventuras de Juan Moreira (1910), así como más tarde lo hace El Juguete rabioso (Roberto Arlt, 1926). A este corpus sumo "Memorias de un vigilante" (1954 [1897]) de Fray Mocho -en particular la segunda parte, "Mundo Lunfardo"- y "Toribio Torres, alias «Gardelito”" (Kordon, 1961 [1956]).

El concepto de "transculturación" permite interpretar el vínculo entre la picaresca española y la literatura vernácula. Según Ángel Rama (2008), la originalidad de las literaturas latinoamericanas viene dada por el "afán internacionalista". Esto es, el esfuerzo de crear lenguajes simbólicos propios en el entramado que se produce entre escritores y consumidores, en un flujo de doble sentido que tiene también en cuenta las relaciones entre las capitales y las provincias. Así, en todo proceso de este tipo "habría pérdidas, selecciones, redescubrimientos e incorporaciones. Estas cuatro operaciones son concomitantes y se resuelven todas dentro de una reestructuración general del sistema cultural, que es la función creadora más alta que se cumple en un proceso transculturante" (Rama, 2008, p. 47). Pueden distinguirse tres niveles de transculturación: en la lengua, la estructura literaria y la cosmovisión (ídem, p. 56). A su vez, resulta pertinente pensar este problema desde la noción de "sistema", desarrollada por Antonio Cándido para Brasil y extendida por Rama hacia Latinoamérica. Así, la manera de entender la literatura de una zona como un sistema coherente es posible a partir de la existencia de una serie de temas, formas, medios expresivos, vocabularios, inflexiones lingüísticas, un público consumidor vinculado a los creadores y "un conjunto de escritores que atienden las necesidades de ese público y que por lo tanto manejan los grandes problemas literarios y socioculturales" (Mejía Toro, 2014, p. 176). En tanto el período de publicación de las obras de Payró (El casamiento de Laucha, Pago chico y Divertidas aventuras de Juan Moreira) coincide con la autonomización del campo literario y las mismas cumplen con las características sintetizadas por Mejía Toro, es posible tomarlas como elementos que forman parte de un sistema y se extienden en el tiempo ${ }^{8}$.

Hacia fines del siglo XIX, Fray Mocho apareció como un exponente del "criollismo", entendido como una línea entre "el regionalismo, el costumbrismo rural y suburbano e incluso el folklore" (Dos Santos, 1968, p. 667). Director de Caras y Caretas desde sus inicios (1897), su obra literaria tiene una fuerte impronta cronística. Su Memorias de un vigilante relata el devenir de un joven de provincia que por desconocer lo que era la libreta de enrolamiento, acaba trabajando como policía. Llega así a la ciudad, que lo deslumbra, y empieza a reconocer sus personajes desde su rol como agente de la ley. ${ }^{9}$ El volumen se compone de capítulos breves y se divide en dos partes en buena medida autónomas, ya que pasa de unas memorias a unos episodios con afán tipificante y el estilo del relato cambia considerablemente. El segundo apartado, "Mundo lunfardo", describe diversas formas de la delincuencia en la ciudad de Buenos Aires, a cuyos exponentes llama tanto "pícaros" como "pillos". Primero describe las diferencias entre el ladrón criollo -compadritos o sirvientesy el extranjero, que era el más abundante y difícil de reconocer puesto que "viste como un caballero, como un compadre o como un artesano (...): adopta la forma necesaria para cada una de sus empresas oscuras y malignas" (Mocho, 1954, p. 177). Luego establece la siguiente clasificación: 
los punguistas, o limpiabolsillos; los escruchantes, o abridores de puertas; los que dan la caramayolí, o la biaba, o sea los asaltantes; los que cuentan el cuento, o hacen el scruscho, vulgarmente llamados estafadores, y, finalmente, los que reúnen en su honorable persona las habilidades de cada especie: estos estuches son conocidos por de las cuatro armas (Mocho, 1954, p. 179).

En esa categorización, los "contadores del cuento" son quienes ocupan un lugar más elevado, hasta incluso no identificarse a sí mismos dentro de la familia delincuencial. ${ }^{10}$ Mocho los describe como la "aristocracia" de los pillos y reconoce su inteligencia. Así, dedica varios episodios a narrar algunas de sus ocurrencias, desplegando la inventiva de sus puestas en escena. A pesar de que el punto de vista del narrador está definitivamente del lado de la ley y de que esos relatos tienen como objetivo dejar en evidencia el modus operandi de estos sujetos, en esa selección y jerarquización se identifica una cierta fascinación por la actividad de los cuenteros, que evidentemente ocupaban un lugar de relevancia dentro de ese mundo "lunfardo"1.

Según Dos Santos, Fray Mocho comparte con Payró: “un digno lugar dentro de las filas del realismo" (1968), la práctica del periodismo, el gusto por el relato breve, la clara postura criollista y la certeza de que la misión de un escritor de esa época era ser retratista de la realidad. Roberto Payró es uno de los autores que más vehementemente promulgó para la constitución del campo literario. Asimismo, tenía una fuerte conciencia del poder de sus escritos, a través de los cuales presentó una crítica a las costumbres criollas. Produjo una obra copiosa e importante entre fines del siglo XIX y comienzos del XX. El corpus abordado aquí constituye un "fresco" de un pueblo imaginado-Pago Chico- pero con un referente cercano -cualquier pueblo de provincias, especialmente de la zona centro del país. ${ }^{12}$ De diversas maneras, estas obras se apropian de la forma de la picaresca española. Podemos tomar entonces los niveles propuestos por Rama para pensar los procesos de la transculturación: lengua, estructura literaria y cosmovisión.

En cuanto a la lengua, Pagés Larraya indicaba que la innovación de El casamiento... constituía en arrasar "con las convenciones del criollismo romántico" (1968, p. 667), produciendo una síntesis entre la picaresca y la tradición gauchesca. A su vez, Generani señala que Payró se distanciaba del naturalismo al mitigar las leyes de la herencia con los elementos de la picaresca española y su carga de humorismo, lo cual exponía "la simpatía por aquellas conductas que aparentemente exponía para censurar” (2002, p. 79). Esto puede observarse a nivel del habla, ya que la obra está repleta de modismos que hacen a la concepción del mundo del personaje, además de incorporar la sonoridad de las lenguas de otros personajes, como la propia Doña Carolina o Ño Cipriano. En cambio, en Las divertidas aventuras..., los términos criollos se encuentran entrecomillados, marcando una distancia entre el narrador y lo narrado. Se trata de un recurso retórico para la configuración de su personaje, quien en su trayecto de vida pretende distanciarse de los modos de provincia para construirse un perfil cosmopolita. La presencia de la lengua criolla, sin embargo, atraviesa ambos relatos, constituyendo un aspecto característico.

A nivel de estructura, Payró construye distintas instancias enunciativas en cada una de estas obras. En El casamiento..., el narrador se presenta apenas como un reproductor de 
la voz del personaje, recreando el estilo del relato oral, con fuerte asiento en la cultura popular. En ambos casos, el habla criolla y la extranjera (italiana, especialmente) son recreadas desde su sonoridad y también su concepción metafórica. En Las divertidas... la estructuración del relato es de unas memorias, es decir, la primera persona en el pasado. La única nota al pie de la novela introduce la presencia de un "copista", es decir, que subraya la organización ficcional de la obra. A pesar de que en ambas obras aparece un mediador entre el personaje y el relato, se presentan prácticamente como amanuenses, prevaleciendo completamente la narración de los protagonistas. Se mantienen, entonces, la primera persona y la remisión al pasado, asemejándose en este sentido a El lazarillo o El Buscón. Ahora bien, respecto a la visión de mundo, esta es necesariamente distinta, porque el contexto es diverso. En la tradición hispana, los protagonistas son descastados que sufren la violencia material y simbólica de sus amos dentro de una estructura feudal inalterable y, por lo tanto, las tretas que llevan adelante son defensivas y con ansias vindicativas. La trilogía de Payró se ubica en una sociedad absolutamente diversa: en un país con una ordenación política democrática, aun en formación y con numerosos defectos pero que, por esa misma razón, admite cambios. La crítica entonces apunta a las clases hacendadas y a quienes forman parte de esas instituciones corruptas.

Ese gesto crítico está plasmado fundamentalmente a través del protagonista de Divertidas aventuras..., la novela que produce diferencias más significativas respecto de los casos españoles. Allí, el protagonista es hijo de un hacendado de provincia y, por lo tanto, lejos se encuentra la historia de retratar las inclemencias que le ocurren a un lumpen. Por el contrario, Mauricio Gómez Herrera (el doble apellido en el ambiente criollo, por aquel entonces, era signo de alcurnia) es hijo único de un hombre que posee capital económico y social. Así, lejos de enfrentarse a dificultades materiales, sus andanzas son las de un sujeto que tiene capacidad de cálculo para escalar de posición social. Lejos de la supervivencia, Mauricio Gómez Herrera constituye un sujeto cínico, que no duda en aprovecharse de los demás para mejorar su posición social y estándar de vida. De esta manera, el tipo de personaje se aleja de la matriz ideológica de la picaresca originaria. La crítica de las costumbres se dirige hacia el propio sujeto del relato, quien forma parte de esa sociedad corrupta que se examina. No es un observador, sino un fruto consumado de las tretas y los mecanismos -de las estrategias, en términos de Michel De Certeau (1996)- que poseen quienes forman parte del poder político. Payró alude así a la política criolla, particularmente a lo que él considera vicios de la Generación del 80.

El título del libro encubre este propósito. No hay "aventuras" en sentido riguroso; sí una suma de peripecias, pero que están debidamente programadas y que tampoco son "divertidas" ciertamente. La idea de "nieto" plantea una sucesión generacional, que permite inscribir el origen de lo que se critica en la década del ochenta. La alusión a Juan Moreira es significativa, ya que pertenecen a clases sociales bien diferentes. Sin embargo, este personaje resulta funcional como referente de la corrupción de la década mitrista y también -es posible pensarlo- como atractivo para un público más amplio. No ocurre lo mismo con Laucha, protagonista del relato breve. Señala Pagés Larraya: 
En Laucha la picardía y el vicio ni se atenúan ni se justifican; en cambio la condena moral de Gómez Herrera y su correlativo valor crítico frente a las lacras del país se erigen sobre una contradicción íntima que el arte del novelista no logra salvar (1968, p. 653). ${ }^{13}$

Esta diferencia de tratamiento se debe a la procedencia social del personaje, que cambia sustancialmente el foco de la crítica, ya que las consecuencias de sus acciones tienen alcances muy distintos. Payró produce entonces una particular apropiación de la picaresca para encauzar su crítica a las formas políticas de la clase criolla, en un momento donde las discusiones sobre la unidad y rumbo del país aún estaban presentes, especialmente en torno al Centenario de la Revolución de Mayo.

En 1977, este relato tuvo su versión cinematográfica. Fue dirigida y producida por Enrique Dawi, realizador que participó en espacios de formación ligados a la Generación del 60 aunque no se lo considere parte de ella estrictamente. En aquellos años dirigió algunos largometrajes y luego se incorporó en la industria. Sin embargo, este largometraje independiente constituye una iniciativa de corte autoral. Hay un interés específico por recuperar la obra de Payró y realizar con ello un producto popular. ${ }^{14}$ La película se asienta firmemente sobre la obra de Payró, recreando el universo originario de la fábula, a lo que agrega algunas líneas secundarias y modifica -de manera sustancial- el final, convirtiéndolo en un happy end. ${ }^{15} \mathrm{Al}$ igual que en el cuento, se trata de un relato enmarcado por un diálogo entre Laucha y un narrador, que, en este caso, representa al propio Payró en su rol de cronista. El encuentro inicial se realiza en un galpón donde unos hombres juegan a la pelota-paleta y otros apuestan. Un plano contrapicado presenta a Laucha en el balcón rodeado de semejantes, detrás de una pintada que reza "Prohibido hacer apuestas". No obstante, todos los que están allí se reúnen por ese motivo. Ese plano, que incluye la explicitación de la norma y su trasgresión, ya adelanta el universo moral de la historia. El desarrollo más extenso de los personajes del cura y el comisario, ambos estafadores que utilizan su rol institucional para conducir sus fraudes, también subraya la noción de una corrupción generalizada.

\section{El aprendizaje de la simulación}

En El juguete rabioso, Arlt organiza el relato de dos maneras: como "memoria", ya que se trata de una crónica autobiográfica, y como "novela de aprendizaje", dado que el protagonista alcanza saberes y hay una búsqueda de verdad (Capdevila, 2002, p. 229). La relación con la picaresca, según la misma autora, viene dada también por la suma progresiva de las peripecias como principio constructivo. El aspecto que ubica esta obra como un hito importante en el recorrido entre pícaro y chanta viene dado por lo que explica Visconti: "la ficción arltiana reúne todas las formas de la transgresión, la marginalidad, la desvalorización del trabajo y la picardía urbana en función del ansia de dinero" (Visconti, 2015, p. 27). En Silvio Astier, el protagonista, se destacan su poder de observación y también su capacidad inventiva, asociada a la manera en que mira el mundo. Él es un joven proletario que posee 
conocimientos sobre el mundo delictivo, pero también muchos otros literarios y científicos; así como también tiene la intención de incorporarse de manera útil a la sociedad (aunque sea rechazado). Arlt inscribe a su personaje en un espacio definitivamente urbano, aunque marginal. Como ha indicado Jitrik, los trabajos a los que accede Astier son en verdad "formas de robo invertido: el que trabaja es robado" (1976, p. 114). Por eso, el protagonista exhibe cierto orgullo por conseguir el dinero a través de timos: "Sí, el dinero adquirido a fuerza de trapacerías se nos fingía mucho más valioso y sutil" (Arlt, 1993, p. 15). ${ }^{16}$

Afirmaba David Viñas sobre el grotesco, género teatral que encontró su máxima expresión en los mismos años en que Arlt produjo esta obra: "si la infracción respecto de la norma implica creatividad, el recurso a la inmediatez mágica del robo en reemplazo del cotidiano empecinamiento del trabajo (y, en gran medida, el dinero ${ }^{17}$ que se sublima) al desmaterializar, poetiza." (Viñas, 1996, p. 112). De esta forma se afianzaban los imaginarios míticos en torno al dinero en un tiempo durante el cual las transformaciones producidas por la inmigración en la sociedad porteña se vigorizaban. La referencia al teatro no es fortuita, ya que el mismo Arlt escribió obras trascendentes. En ellas, Horacio González encuentra que la simulación es un motivo recurrente, pero no solo como impulso de las tramas, sino como fundamento del arte teatral, como expresión de su ontología. De este modo, Arlt descubre "la compulsión a la impostura como raíz profunda de la teatralidad del sujeto" (idem 2000, p. 27). ${ }^{18}$ En El juguete rabioso, Astier recurrentemente finge para alcanzar sus objetivos. El texto exhibe sus procesos mentales y justificaciones. En suma, más allá del vínculo de El juguete rabioso con la picaresca, interesa destacar aquí cómo se articulan en su obra nociones como teatralidad, representación, farsa y puesta en escena, que son consustanciales al chanta. ${ }^{19}$

En 1956, Bernardo Kordon, quien reconocía la influencia de Arlt en su escritura, publicó “Toribio Torres, alias «Gardelito”. Un cuento extenso, que narra las aventuras de su protagonista y narrador, también un joven marginal que, atento a las debilidades de los demás, halla en su capacidad de engaño un sistema de supervivencia. Su "hacerse a sí mismo" se traduce en convertirse en "cuentero", lo cual propone un vínculo evidente con el oficio del escritor. Tuvo una adaptación cinematográfica en 1961 a cargo de Lautaro Murúa, la cual resulta un ejemplo significativo para analizar la forma que cobra el chanta en el cine moderno. Mientras que el relato literario continúa la tradición realista propia de su medio y propone una identificación con el joven protagonista, la película de Murúa constituye un claro caso de ruptura con los sistemas clásicos de representación. Importante exponente de la Generación del 60, el filme establece un distanciamiento crítico con su protagonista, que no genera empatía hacia él como solía ocurrir en el cine previo. Así, aunque se presentan las circunstancias sociales adversas para Toribio, su accionar no es justificado. Hay una mirada ética sobre su modo de actuar que no autoriza sus embustes, aunque tampoco su muerte anticipada. Aquí al igual que en El juguete rabioso, ocurre que las estafas suben de escala: mientras que al comienzo Toribio trata de quedarse con unos pesos convenciendo a una señora de clase alta, al final los negocios implican el contrabando y connivencia con actores políticos. Al convertirse en "cuentero" casi como un oficio, la organización de ficciones se vuelve concomitante al accionar delictivo de Toribio, quien de este modo se emparenta con el chanta. El relato de Kordon comienza presentando los talentos, ilusiones 
y desencantos de Gardelito; en cambio el filme desde sus inicios establece un comienzo sombrío, dominado por los timos que realiza el protagonista en un grupo de maleantes. Los enfoques de cada uno de los textos son bien diferentes debido a la relación que establecen con las tradiciones de representación propias de su medio expresivo, produciendo acentos distintos sobre la historia. Sin embargo, la figura del cuentero funciona como una caja de resonancia que expone las dificultades de los jóvenes marginales en la transición hacia los años sesenta. ${ }^{20}$

\section{Conclusiones}

Para los autores abordados -Hernández, Mocho, Payró, Arlt y Kordon- la práctica periodística fue clave en su conformación como escritores. No solo por los temas comunes de interés, donde la crónica ciudadana y la astucia para los robos y estafas ocupaban un espacio importante -fundamentalmente para los cuatro últimos-, sino también para delinear su estilo, ligado siempre a diversas variantes del realismo. De esta manera se configura en la literatura argentina un estereotipo que posee antecedentes en otras corrientes literarias, pero que se nutre intensamente de las observaciones sobre la realidad circundante. Así, se delinea el tipo del "cuentero" en un doble sentido: como aquel que narra su historia ${ }^{21}$ y también como el que crea engaños ingeniosos para sacar una ventaja o aprovecharse de los demás. El placer por crear ficciones, ponerlas en práctica y relatarlas es su rasgo constitutivo.

La preocupación por hacer una crítica a las instituciones políticas desde la ficción es una constante dentro en las artes argentinas, así como también la inquietud por la corrupción de las clases políticas y acomodadas. Este último asunto volverá repetidamente, especialmente en el cine, donde la figura de personajes populares como el chanta permite plasmar estas observaciones críticas. En este sentido, en la medida en que el personaje permanece dentro de su clase social de origen, sus trapacerías, aunque puedan ser enjuiciadas, muchas veces son presentadas como actos ingeniosos y en alguna medida resistentes frente a un sistema injusto. En cambio, si el chanta forma parte de las clases políticas o del poder económico, entonces su actuar se conforma como una serie de actos corruptos, en tanto poseen consecuencias sobre las clases populares. En esta dualidad radica la ambivalencia del estereotipo del chanta. Su transversalidad en productos industriales tanto como en otros de corte autoral y político indica su capacidad de apelación a un imaginario ligado a lo cultural-nacional en la búsqueda de sentidos que se actualizan en diversos contextos históricos. Conocer sus antecedentes en diversos medios y tradiciones artísticas permite trazar líneas de largo alcance y comprender el porqué de la permanencia del tipo. 


\section{Referencias bibliográficas}

Altamirano, C., y Sarlo, B. (1980). La Argentina del Centenario: Campo intelectual, vida literaria y temas ideológicos. Hispamérica, 25-26, 33-59.

Amossy, R., y Herschberg Pierrot, A. (2010). Estereotipos y clichés. Eudeba.

Arlt, R. (1993). El juguete rabioso. Losada.

Bellone, L. (2020, Noviembre 11). Los consejos del Martín Fierro y los del viejo Vizcacha en la sociedad argentina. Pagina/12. https://www.pagina12.com.ar/305098-los-consejosdel-martin-fierro-y-los-del-viejo-vizcacha-en-l

Bracchi, C., y Paulozzo, M. (2011). Diseño Curricular para la Educación Secundaria 60 año: Literatura. Dirección General de Cultura y Educación de la Provincia de Buenos Aires. http://servicios.abc.gov.ar/lainstitucion/organismos/consejogeneral/disenioscurriculares/secundaria/sexto/materias comunes/Literatura_6.pdf

Capdevila, A. (2002). Las novelas de Arlt. Un realismo para la modernidad. En N. Jitrik y M. T. Gramuglio (Eds.), Historia crítica de la literatura argentina. Vol. 6. El imperio realista Vol. 6. El imperio realista (pp. 225-244). Emecé.

Conde, O. (2017). Aportes al estudio del lunfardo: acreencias y deudas de la investigación lingüística argentina. Signo y Seña, 32(Jul-Dic), 1-20.

de Certeau, M. (1996). La invención de lo cotidiano. I. Artes de hacer. Universidad Iberoamericana.

de Diego, J. L. (1998). La novela de aprendizaje en Argentina - 2a parte. Orbis Tertius, 4(7), 15-31.

Del Campo, A. M. (1945). Los Consejos del Viejo Vizcacha. Buchieri.

Dos Santos, E. (1968). El criollismo: Fray Mocho. En A. Prieto (Ed.), Historia de la literatura argentina. Vol. II. El desarrollo (pp. 667-672). Centro Editor de América Latina.

Fernández-Montesino, A. (2016). Los estereotipos: definición y funciones. Revue détudes Ibériques et Ibéro-Américaines, 10, 52-62. https://bit.ly/2LGsf5k

Generani, G. (2002). Roberto J. Payró. El realismo como política. En N. Jitrik y M. T. Gramuglio (Eds.), Historia crítica de la literatura argentina. Vol. 6. El imperio realista (pp. 61-89). Emecé.

González, H. (2000). Simulación y metamorfosis en el teatro de Roberto Arlt. En O. Pellettieri (Ed.), Roberto Arlt. Dramaturgia y teatro independiente (pp. 25-33). Galerna. Hernández, J. (1950). Martín Fierro. Losada.

Jitrik, N. (1976). Entre el dinero y el ser (Lectura de El juguete rabioso de Roberto Arlt). Dispositio, 1(2), 100-133.

Kordon, B. (1961). Vagabundo en Tombuctú, Alias Gardelito y otros relatos. Losada.

Laera, A. (2014). Ficciones del dinero. Argentina, 1890-2001. Fondo de Cultura Económica.

Mejía Toro, E. A. (2014). Ángel Rama y Antonio Candido: la integración del Brasil en el sistema literario latinoamericano. Literatura: Teoría, Historia, Crítica, 16(1), 165-192.

Mocho, F. (1954). Obras completas. Schapire. 
Pagés Larraya, A. (1968). Tradición e innovación en la picaresca: matices de El casamiento del laucha. Cuadernos Hispanoamericanos, 224-225, 649-674.

Payró, R. (1906). El casamiento de Laucha. http://www.cervantesvirtual.com/obra-visor/ el-casamiento-de-laucha/html/ff368d0e-82b1-11df-acc7-002185ce6064_2.html

Payró, R. (1957). Divertidas aventuras del nieto de Juan Moreira. Losada.

Pellettieri, O. (2001). De Totó a Sandrini. Del cómico italiano al "actor nacional" argentino (O. Pellettieri [ed.]). Galerna e Instituto Italiano de Cultura en Buenos Aires.

Rama, Á. (2008). Transculturación narrativa en América Latina (2da. ed.). El Andariego.

Rodríguez Riva, L. (2020). El "cuentero" como punto de encuentro entre la literatura popular y el cine moderno: Alias Gardelito. $452^{\circ} \mathrm{F}, 23,162-178$.

Sánchez Lobato, J. (1999). Biografía de Alonso Zamora Vicente. Cervantesvirtual. http://www. cervantesvirtual.com/portales/alonso_zamora_vicente/autor_apunte_biografico/\#nota1

Vicente, A. Z. (1962). Qué es la novela picaresca. Columba. http://www.cervantesvirtual. com/nd/ark:/59851/bmccj8c1

Viñas, D. (1996). Armando Discépolo: grotesco, inmigración y fracaso. En Literatura argentina y política II. De Lugones a Walsh (pp. 99-143). Sudamericana.

Visconti, M. (2015). Cine y dinero: imaginarios ficcionales y sociales de la Argentina (19782000) [Tesis de Doctorado, Universidad de Buenos Aires]. http://repositorio.filo.uba.ar/ handle/filodigital/6045

\section{Filmografía}

Dawi, E. (1977). El casamiento de Laucha. Producciones Dawi.

Martínez Suárez, J. (1975). Los chantas. Cinematográfica Victoria.

Murúa, L. (1962). Alias Gardelito. Producción Leo Kanaf.

Solanas, F. (1972). Los hijos de Fierro. Producción Edgardo Pallero.

\section{Notas:}

1. Término que refiere al cine producido a partir de los años sesenta y comprende tanto largometrajes cercanos a la modernidad cinematográfica como otros de producción industrial.

2. Actualmente, de los años asignados al estudio de la literatura en el secundario, el primero está destinado a las formas míticas y fabulosas, épicas y trágicas; y el segundo, a las formas realistas, miméticas, fantásticas y maravillosas. En el corpus sugerido para el último año, también se encuentra Divertidas aventuras del nieto de Juan Moreira (Bracchi y Paulozzo, 2011). 
3. Historia de la vida del Buscón (1626) de Francisco de Quevedo.

4. Novela breve de Miguel de Cervantes, incluida originalmente en Novelas ejemplares (1613).

5. Zamora Vicente fue un filólogo español interesado por las literaturas y cultura hispanoamericanas. Durante sus años en la ciudad de Buenos Aires (1948-1952), tuvo a su cargo la dirección del Instituto de Filología de la Facultad de Filosofía y Letras, Universidad de Buenos Aires (Sánchez Lobato, 1999). El volumen Qué es la novela picaresca fue recuperado por la Biblioteca Virtual Miguel de Cervantes, que lo puso a disposición en su archivo digital.

6. Liliana Bellone (2020) ha señalado atinadamente la confusión por la cual se le atribuyen versos de Vizcacha a Martín Fierro. Según ella, la inversión se produce porque ambos se expresan desde la cadencia sentenciosa y la modalidad apelativa desde el lugar del "guacho". A esta interpretación sobre la estructura de los dichos, yo sumaría una explicación que tiene que ver, por un lado, con la modificación del punto de vista de Martín Fierro en la segunda parte -que se contrapone al de la primera- y, por otro, a la proyección desde los lectores que tiende a adjudicar esta sabiduría popular, ligada a la viveza, al personaje positivo.

7. "Todo aquel que por cualquier causa haya recorrido la campaña argentina, tiene que haberse encontrado, necesariamente con uno de esos viejos criollos de extraordinaria locuacidad (...) En cada uno de esos criollos revive la figura gloriosa del mentado Viejo Vizcacha, dicharachero y entretenido" (Del Campo, 1945, p. 6).

8. El momento histórico en el que se publican es el de la configuración de un campo intelectual autónomo, que recibe el influjo de las ideas civilizatorias de dirigentes de los años ochenta (fundamentalmente, Mitre) y pretende responderles. Como han descripto Altamirano y Sarlo (1980), es hacia el Centenario cuando se discuten categorías muy importantes, como la definición de la nación y quiénes deben ser sus representantes. En el contexto del modernismo, un grupo de escritores busca diferenciar su esfera de trabajo, autonomizarla y producir también un efecto de sentido sobre la realidad que cuestione (incluso, en algunos casos, invierta) los sentidos dominantes en ese momento. Se trata, a su vez, del período de auge de la inmigración europea, que no cumple con las expectativas de aquellos políticos que la habían motivado. A su vez, los inmigrantes se asientan en las ciudades, puesto que la propiedad de la tierra se mantiene concentrada en la oligarquía, y quedan así expuestas cada vez más fuertemente las desigualdades entre clases sociales. Es decir, se trata de las condiciones propicias para el tipo de personaje oportunista al que se orienta este estudio.

9. Basado en su propia experiencia como comisario, diez años antes publicó Vida de los ladrones célebres de Buenos Aires y sus maneras de robar. Sin embargo, por considerar que se trata solo de un "mero álbum fotográfico" y que su valor literario es nulo, no fue incluido en sus obras completas (Mocho, 1954, p. 143).

10. Mocho narra algunas de las justificaciones que exhibían estos sujetos: “¡Nosotros lo que hacemos es embromar a quien nos tiene por zonzos!", o bien consideraban que su 
acción funcionaría como un recupero de las ganancias que los extranjeros se llevarían del país (Mocho, 1954, p. 190).

11. Durante mucho tiempo se utilizó el término "lunfardo" como sinónimo del habla de los delincuentes. En esta investigación adopto la acepción que lo define como "un repertorio léxico constituido por voces y expresiones populares de diversa procedencia utilizados en alternancia o abierta oposición a los del español estándar" (Conde, 2017, p. 2), por eso el entrecomillado. Aquí, sin embargo, "lunfardo" refiere explícitamente al mundo de los delincuentes.

12. Si bien "Pago Chico" y "Nuevos cuentos de Pago Chico" forman parte de esta trilogía, no responden a la forma de la novela de aprendizaje, motivo por el cual los aparto de este recorrido. Competen, igualmente, las observaciones sobre las temáticas, tipo de personajes y cosmovisión que presentan los otros volúmenes.

13. En este sentido, sostiene Generani que

el hecho de que su relato nos indique que quien habla no es peor que los pillos institucionales -como el comisario o el cura-, parecería ser un atenuante frente a un juicio moral posible, pues conduce a pensar en una inmoralidad universal, rasgo característico de la picaresca española que se suma a otros de la misma procedencia, tales como el desenmascaramiento de la hipocresía y la ausencia de maniqueísmo y de mensaje moral (Generani, 2002, p. 80).

14. El guion fue realizado por el mismo Dawi junto con Enrique Villalba Welsh, un prolífico guionista del período clásico. Acertadamente, Laucha está encarnado por Luis Landriscina, cómico que se caracteriza por humor propio del relato largo, con tonada provinciana, donde lo que importa es el desarrollo y no tanto el remate.

15. La escena extra se realiza sobre los títulos de cierre, en una secuencia musicalizada y sin diálogos. Tras la conversación con Payró, Laucha toma conciencia de su desatino y regresa al hogar, para reconciliarse con Carolina.

16. La obra puede incorporarse a lo que Alejandra Laera denominó "ficciones del dinero" en la literatura argentina, como aquellas donde el metálico "ya no sigue más la lógica de la tradición (familiar, hereditaria y previsible), sino la lógica de la circulación, el intercambio y el juego (social, especulativa y azarosa)" (Laera, 2014, p. 71).

17. Sobre este asunto, cfr. Laera (2014) en literatura y Visconti (2015), para el cine.

18. Así, en el preciso instante en que Astier se convierte en traidor ocurre una "torsión del yo, momento esencial sobre el que descansa el desvío hacia la verdad dramatúrgica" (González, 2000, p. 29).

19. El juguete rabioso tuvo una adaptación cinematográfica en 1984, dirigida por Aníbal di Salvo. La película no solo se asienta en el relato literario, sino que reconstruye un mundo histórico-ficcional que rodea a la figura de su autor. De hecho, subraya y amplía ciertos matices autobiográficos de la obra, ya desde la configuración visual de su protagonista que remite al joven Roberto Arlt.

20. Un análisis pormenorizado sobre esta relación puede encontrarse en Rodríguez Riva (2020).

21. Ese contar la propia historia se asocia a la manera en que se presentan frente a los demás y crean un aura de viveza, ingenio y superioridad. En Los chantas esto es tematizado 
reiteradamente por el Flaco, quien dice: “¿Y cómo querés que la cuente?”, en el momento en que su versión es expuesta como falsa y se evidencia, por lo tanto, su fragilidad.

\begin{abstract}
Among the typical figures to represent popular sectors in Argentine cinema there is the chanta. This character synthesizes features of Spanish rogues, as well as it incorporates the heritage of popular Italian actors. From Harlequin to Lazarillo, both representational traditions intersect to result in a type with local peculiarities. In this article, I propose to reconstruct the appearance of the "rogue" in Argentine literature and to establish links with national cinematography. Thus, this work can be understood within imagology, an area of studies dedicated to the critical review of national characterizations. Its main objective is to understand the discourses about a society, assuming that "images do not reflect identities, but rather constitute possible identifications" (Leerssen, 2007). I utilize the notion of stereotype as a figure that synthesizes but also contributes to consolidate certain social imaginaries (Amossy and Herschberg Pierrot, 2010). The methodological perspective to explore this identity configuration is cultural history.
\end{abstract}

Keywords: popular character - rogue - chanta - stereotype - imagology - comparative literature - cultural history.

Resumo: Entre as figuras típicas para representar os setores populares do cinema argentino está o "chanta". Este personagem sintetiza características de malandros espanhóis, bem como incorpora a herança de atores italianos populares. Do Arlequim ao Lazarilho, ambas tradições de representação se cruzam para resultar em um tipo com peculiaridades locais. Neste artigo, proponho reconstruir a aparência do "malandro" na literatura argentina e estabelecer vínculos com a cinematografia nacional. Assim, este trabalho pode ser compreendido dentro da imagologia, área de estudos que se dedica à revisão crítica das caracterizações nacionais, cujo objetivo é compreender os discursos gerados sobre uma sociedade, entendendo que "as imagens não refletem identidades, mas sim constituem possíveis identificações” (Leerssen, 2007). Parto da noção de estereótipo como uma figura que sintetiza e além disso ajuda a consolidar certos imaginários sociais (Amossy e Herschberg Pierrot, 2010). A perspectiva metodológica para investigar essa construção da identidade do plebeu é a história cultural.

Palavras chave: personagem popular - malandro - chanta - estereótipo - imagologia - literatura comparada - história cultural.

[Las traducciones de los abstracts fueron supervisadas por el autor de cada artículo] 